\title{
Ürolojik Laparoskopik Cerrahide Lazer Kullanımı
}

\author{
Can Aykanat ${ }^{1}$, Çağdaş Şenel ${ }^{1}$, Altuğ Tuncel ${ }^{1}$
}

${ }^{1}$ Sağlık Bilimleri Üniversitesi, Ankara Numune Eğitim ve Araştırma Hastanesi, Üroloji Kliniği, Ankara

\section{Giriş}

T azer kelimesi, "Light Amplification of Stimulated Emission ـof Radiation" teriminin Türkçe kısaltmasıdır. Lazer, 1960 yılında Theodorev H. Maiman tarafından keşfedilmiş olup üroloji alanında ilk kez 1966 yılında Parsons tarafından kullanılmıştır. Günümüzde, teknolojik ilerlemeler sayesinde başta benign prostat hiperplazisi ve üriner sistem taş hastalığ olmak üzere birçok ürolojik cerrahide kullanılmaktadır (1).

Lazer, koagülasyon ve vaporizasyon fonksiyonunu eş zamanlı olarak gerçekleştirebilmesinin yanında ödem, fibrozis ve stenoz riskini de büyük oranda azaltmaktadır. Bu özellikleri ile lazerin laparoskopik uygulamalarda da kullanılabileceği düşünülmüştür (1). Henüz laparoskopik cerrahide çok sık kullanılmasa da, lazer enerjisinin klinik ve deneysel araştırmalarda esas olarak laparoskopik parsiyel nefrektomi (LPN), laparoskopik radikal prostatektomi (LRP) ve laparoskopik pyeloplasti (LP)'de kullanımı bulunmaktadir. Günümüzde laparoskopik cerrahide bugüne kadar kullan1lan lazer türleri: $\mathrm{CO}_{2}$, Neodymium:Yttrium-Aluminum-Garnet (Nd:YAG), Holmium:Yttrium-Aluminum-Garnet (Ho:YAG), Potasyum-Titanil-Fosfat (KTP) ve Thulium lazerdir.

$\mathrm{Bu}$ derlemede, ürolojik laparoskopik cerrahide lazer kullanımı güncel literatür bilgileri eşliğinde okuyucular ile paylaşılacaktır.

\section{LPN'de Lazer Kullanımı}

Günümüzde görüntüleme yöntemlerinin sık kullanılması nedeni ile rastlantısal, semptomatik olmayan, küçük boyutlu, çoğunluğu PN adayı olan renal kitleler sık saptanmaktadır. LPN'de hiler klempleme süresinin mümkün olduğunca kısa tutulması, böbrek fonksiyonlarının korunması açısından önem arz etmektedir. Kitle eksizyonu sırasında etkili hemostaz yapabilmesi sebebi ile lazer teknolojisinin PN operasyonlarında faydalı olabileceği düşünülmüştür (2).

PN'de lazer kullanımına ait ilk çalışma 1972 yılında $\mathrm{CO}_{2}$ lazer kullanılarak yapılmıştır (2). Ancak takip eden çalışmalar sonucunda $\mathrm{CO}_{2}$ lazerin $0.5 \mathrm{~mm}$ çapından daha büyük damarları koagüle edemediği için hemostazda tek başına yeterli olmadığı sonucuna varılmıştır. İlerleyen yıllarda lazer teknolojisi deneysel ve klinik çalışmalarda APN'de kullanılmıştır (3-6). Yapılan çalışmalar doğrultusunda lazer yardımlı açık PN'nin standart açık PN'ye belirgin bir üstünlük sağlamadığı sonucuna varılmış ve lazer teknolojisi açık PN kullanım pratiğinde kendisine yer bulamamıştır (2).

Literatürde, LPN'de lazerin klinik kullanımı ile ilgili ilk klinik çalışma Lotan ve ark.'ları tarafından 2002 yılında yayımlanmıştır (7). Bu çalışmada, 3 hastaya (Duplike sistemde non fonksiyone böbrek, dev böbrek kisti, böbrek kanseri) Ho:YAG lazer kullanılarak iki hastada hiler klemplemeye ihtiyaç duyulmadan LPN gerçekleştirilmiştir. Operasyonlarda geç dönem kanama riskinden kaçınmak amacı ile 2 hastada fibrin bazlı yapıştırıcı, 1 hastada selüler oksidisit kullanılmıştır. Bu çalışmada, büyük damarların rezeksiyonu sırasında kanın basınçlı olarak sıçraması ve işlem sırasında duman oluşumu en önemli sorun olarak bildirilmiştir. Yazarlar, lazer teknolojisi ile hiler klempleme ihtiyacı olmadan iyi hemostaz sağlanabileceğini bildirmiştir.

Ogan ve ark.'ları, 10 domuz üzerinde hiler klempleme yapılmadan $980 \mathrm{~nm}$ Diod lazer yardımlı ile LPN deneyimlerini yayımlamıştır (8). Bu çalışmada, \%30 oranında yetersiz hemostaz, \%40 oranında ise ekstravazasyon rapor edilmiştir. Yazarlar, gelişebilecek hemoraji nedeni ile ek hemostatik önlemlere ihtiyaç duyulabileceğinden, insanlar üzerinde yapılacak olan klinik çalışmaların küçük, ekzofitik kitleler ile sınırlandırılması gerektiği sonucuna varmıştır. Knezevic ve ark.'larının çalışmasında (9), 17 hastada Diod lazer yardımlı LPN gerçekleştirilmiştir. On altı hastada sıcak iskemi uygulanmış ve ortalama sıcak iskemi süresi 16 (9-20) dakika olarak bildirilmiştir. Yazarlar, tekniğin sağladığı kısa sıcak iskemi süresini vurgulayıp onkolojik etkinliğin belirlenmesi için daha uzun takip süreli çalışmalara ihtiyaç olduğunu belirtmiştir. Zhou ve ark'larının çalışmasında ise; 5 hastaya 980 nm Diod lazer yardımlı LPN yapılmıştır (10). Tüm hastalarda segmental arter klemplemesi yapılmış ve ortalama klempleme süresi 23 dakika, ortalama kan kaybı ise $60 \mathrm{ml}$ olarak bildirilmiştir. Hiçbir hastada komplikasyon ve pozitif cerrahi sınır rapor edilmemiştir. Bu çalışmanın yazarları, lazer uygulamasının hemostaz açısından başarılı olduğunu ve güvenli bir cerrahi sunduğunu değerlendirmiştir. Ancak cerrahi sırasında karşılaştıkları en önemli sorunun duman oluşumu olduğu rapor edilmiştir.

Moinzadeh ve ark.'ları tarafindan yayımlanan deneysel bir çalışmada, 6 inek üzerinde KTP lazer yardımlı 12 LPN gerçekleştirilmiştir (11). Sadece bir operasyonda hemorajiye bağlı renal klemplemeye ihtiyaç duyulmuş, gelişen hemoraji lazer kullanılarak durdurulmuştur. Diğer operasyonlar ise klemp kullanmadan bitirilmiştir. Yazarlar, $532 \mathrm{~nm}$ dalga boylu KTP lazerin hemoglobulinler tarafından selektif olarak absorbe edildiği için etkili hemostaz sağladığını, ancak cerrahi sırasında görüntüyü bozacak şekilde duman oluştuğunu belirtmiştir. Hindley ve ark.'larının LPN'de $80 \mathrm{~W}$ KTP lazer kullanımını inceledikleri deneysel çalışmada, 4 
domuza hiler klempleme yapılmadan 15 LPN uygulanmış ve sadece bir operasyonda hemostatik Endoklip kullanma ihtiyacı duyulmuştur (12). Çalışma sonucunda yazarlar, tekniğin etkili hemostaz ve mükemmel renal parankimal ablasyon sağladığını vurgulamış, duman oluşumunun azaltılıp görüntünün geliştirilmesi gerektiğini belirtmiştir. Liu ve ark'ları, 80W KTP lazer enerjisi kullanarak domuzlar üzerinde LPN operasyonu gerçekleştirmiş ve operasyon sırasında cerrahi alanı sürekli olarak salin solüsyonu ile irrige etmiştir (13). Bu çalışmanın yazarları, salin irrigasyonunun duman oluşumunu dramatik olarak azalttığını ve lazer kullanımında ortaya çıan duman sorununun büyük ölçüde önüne geçildiğini belirtmiştir. Güncel bir deneysel çalışmada ise, $120 \mathrm{~W}$ KTP lazer yardımlı LPN (KTP-LPN) ( $\mathrm{n}=15)$ ile konvansiyonel LPN (K-LPN) (n=15) domuzlar üzerinde karşılaştırılmıştır (14). Tüm KTP-LPN'ler hiler klempleme yapılmadan gerçekleştirilmiş, K-LPN'lerde hiler klempleme uygulanmıştır. Lazer kullanılan grupta 2 domuz üriner fistül gelişmesi nedeni ile birinci haftada ölmüştür. Diğer grupta ise bir tane domuz kalp yetmezliği nedeni ile ölmüştür. Pozitif cerrahi sınır açısından gruplar arasında farklılık saptanmamıştır. Kan değerleri böbrek fonksiyonları ise operasyon sonrasındaki ilk 24 saatte KTP-LPN grubunda daha kötü bulunmuş; ancak 3-6 hafta arasında düzelme saptanmıştır. Bu çalışmanın yazarlarl, KTP lazerin hayvan modelinde uygulanabilir olduğunu ancak daha fazla çalışmaya ihtiyaç olduğu sonucuna varmıştır.

Thomas ve ark.'ları, böbrek kanseri saptanan 15 hastada sıfır iskemi ile $2013 \mathrm{~nm}$ Thulium lazer yardımlı LPN gerçekleştirmiştir (15). Bu çalışmada, ortalama kitle boyutu, ortalama operasyon süresi ve ortalama kan kaybı sırası ile $2.8 \mathrm{~cm}$, 168 dakika ve $341 \mathrm{ml}$ olarak rapor edilmiştir. Tüm hastalarda operasyon sonrasında serum kreatinin düzeylerinde anlamlı bir değişiklik saptanmamış ve cerrahi sınır negatif olarak raporlanmıştır. Yazarlar, Thulium lazer enerjisinin fonksiyonel ve patolojik sonuçlarının mükemmel olduğu sonucuna varmıştır. Sciarra ve ark.'larının yayımladıkları çalışmada ise; $2013 \mathrm{~nm}$ Thulium lazer kullanarak 10 yüksek riskli hastada açı PN ( $n=7)$ ve LPN ( $n=3)$ gerçekleştirilmiştir (16). Yazarlar, Thulium lazerin her iki yöntemde de kolay uygulanabilir olduğu, tümörün çevre dokudan kesin bir sınır ile rezeksiyonunu sağladığını, özellikle yaşlı ve yüksek riskli hastalarda güvenli bir tedavi yöntemi olduğunu rapor etmiştir.

Sonuç olarak, LPN'de lazer kullanımının en önemli dezavantajları özellikle merkezde yerleşen tümörlerde büyük damarları tam anlamı ile kapatamaması ve işlem sırasında duman oluşumudur. Literatürde yer alan deneysel ve klinik çalışmalarda, lazer yardımlı LPN'nin özellikle küçük ve ekzofitik kitlelerde hemostaz sağlamada başarılı olduğu vurgulanmasına rağmen günümüzde standart yöntemin yerini henüz almamıştır.

\section{LRP'de Lazer Kullanımı}

Günümüzde radikal prostatektomi; açık, laparoskopik veya robot yardımlı olarak yapılmaktadır. Seçilen cerrahi yaklaşımdan bağımsız olarak, penil erektil fonksiyonun korunabilmesi için operasyon sırasında, prostatın posterolateralinde yoğunlaşan ve nörovasküler demet (NVD) olarak da bilinen periprostatik parasempatik liflerin korunması gerekmektedir (17). Günümüzde diseksiyon ve hemostaz amacı ile kullanılan koterler (monopolar veya bipolar) ile ultrasonik kesicilerin çevre dokulara termal hasar verdiği ve bu yüzden kavernozal sinir fonksiyonunu etkiledikleri bilinmektedir (18). Lazerin diseksiyon sırasında etkili hemostaz sağlaması ve çevre dokulara minimal termal hasar vermesi sebebi ile radikal prostatektomi operasyonlarında kullanılabileceği düşünülmüsstür (2).

Literatür incelendiği zaman, LRP'de lazer kullanımına ait ilk çalışma 2007 yılında Gianduzzo ve ark.'ları tarafından yayimlanmistir (19) Sinir koruyucu olmayan LRP planlanan ve 5 hastanın dahil edildiği bu çalışmada, ilk hastaya kontrol amaçlı sağ NVD diseksiyonu soğuk makas ve klip ile yapılmış, sol NVD diseksiyonu ise $1064 \mathrm{~nm}$ dalga boyundaki Nd:YAG lazer yardımı ile gerçekleştirilmiştir. Diğer tüm hastalarda her iki NVD lazer ile diseke edilmiştir. Histopatolojik inceleme sonucunda, lazer kullanılan posterolateral bölgelerde cerrahi sınırın negatif olduğu, lazere bağlı oluşan nekrozun NVD'ten uzak bölgede oluştuğu saptanmıştır. Ortalama kanama miktarı aynı merkezde lazer kullanılmayan olgulara göre daha düşük bulunmuştur (213 ve $292 \mathrm{ml}$ ). Hiçbir hastada idrar inkontinansı bildirilmemiştir. Ancak NVD'in çıkarılması sebebi ile penil erektil fonksiyonların incelenememiş olması çalışmanın en büyük eksikliği olarak gösterilmiştir. Yazarlar uyguladıkları tekniğin kolay uygulanabilen, iyi hemostaz sağlayan ve çevre dokuda minimal hasar yaratan bir teknik olduğunu belirtmiştir.

Bu çalışmanın devamı niteliğinde aynı merkez tarafından yapılan hayvan çalışmasında, 36 köpeğin NVD diseksiyonunda KTP lazer, soğuk makas ve klip ile ultrasonik makas kullanımına göre 3 grup oluşturulmuştur (20). Bu çalışmada, ultrasonik makas kullanımında tepe intrakavernozal basınçlarını belirgin derecede azaldığı, KTP lazer ve soğuk makas kullanımının ise intrakavernozal basınçları etkilemediği rapor edilmiştir. Yapılan histopatolojik inceleme sonucunda, ortalama doku hasar derinliği; KTP lazer, soğuk makas ve ultrasonik makas kullanımında sirası ile $600 \mu \mathrm{m}, 450 \mu \mathrm{m}$ ve $1200 \mu \mathrm{m}$ olarak ölçülmüştür. Ayrıca KTP lazer kullanılan deneklerde, ultrasonik makasa göre daha az termal yayılım ve termal hasar oluştuğu gözlenmiştir. Yazarlar, kavernöz sinir fonksiyonlarının korunmasında KTP lazerin soğuk makas ile karşılaştırılabilir ve ultrasonik makastan üstün olduğunu belirtmiştir.

Sonuç olarak LRP'de lazer kullanımı teorik olarak NVD'nin ve dolayısı ile penil erektil fonksiyonların korunmasını sağlayabilir. Ancak halen bu konuda yapılan çalışmalar sonucunda güvenilir bulgulara ulaşılamamıştır. Bu nedenle lazer enerjisinin LRP'de kullanımı rutin klinik pratiğe girememiştir.

\section{LP'de Lazer Kullanımı}

LP uygulamalarında lazer, laparoskopik cerrahinin ilk başladığ1 yıllarda intrakorporeal sutur uygulamasında zorlanıldığı için anastomoz hattını kuvvetlendirmek amacı ile kullanılmıştır. Etki mekanizması, anastomoz bölgesindeki dokuda lazer ışığının albumin ile etkileşerek ısı artışı ve koagulum ile lehim etkisi meydana gelmesini sağlamaktır (2).

Wolf ve ark.'ları 14 domuzda 22 proksimal üreterotomiyi laparoskopik olarak 4 farklı yöntem (fibrin bazlı yapıştırıcı, lazer, Endo-Stitch ${ }^{\circledast}$ sütür ve klasik sütür) kullanarak anastomoz etmiştir (21). Radyolojik bulgular ve basınç ölçümleri değerlendirildiği zaman, fibrin bazlı yapıştırıcı, lazer ve sütüre göre daha etkin bulunmuştur. Lazer, serbest sütürden daha hızlı uygulanabilir olmasına rağmen, daha etkin bulunmamıştır. Barrieas ve ark.'larının hayvan deneyi çalışmasın- 
da, 50 tane domuzda yapilan LP operasyonunda Diod lazer, fibrin bazlı yapıştırıcı ve standart sütür karşılaştırılmıştır (22). Uzun dönemde ürinom formasyonu lazer ve fibrin bazlı yapıştırıcı kullanılan domuzlarda daha fazla saptanmıştır. Yazarlar, uzun dönemde lazer ve fibrin bazlı yapıştırıcıların klasik sütür tekniğine göre üstün olmadığı sonucuna varmıştır. Shumalinsky ve ark.'larının deneysel çalışmasında ise, 10 çiftlik domuzunda LP sırasında bükülebilir fiberoptik CO2 lazer ile birlikte eş zamanlı kızılötesi ısı sensörü kullanarak lazer uygulaması sırasında ısının 2-3 C0 kalması sağlanmıştır (23). Bir aylık takiplerde piyeloüreteral anastomozda başarılı bir birleşme rapor edilmiştir.

Sonuç olarak, LP'de lazer kullanımı ile ilgili yayınların hepsi deneysel çalışmalardan oluşmaktadır. Bu çalışmaların sonuçlarına gore, LP'de lazer uygulamasının piyeloüretral anastomozun sağlamlığı açısından standart sütüre üstünlüğü rapor edilmemiştir. Bu nedenle lazer enerjisi $\mathrm{LP}^{\prime}$ de günlük klinik pratikte rutin olarak kullanılmamaktadır.

\section{Sonuç}

Avrupa Üroloji Birliği'nin Lazer Teknolojileri Kılavuzu incelendiği zaman (24), lazer yardımlı PN'nin umut veren alternatif bir yöntem olduğu ancak klinik uygulamaya girebilmesi için daha fazla çalışmaya ihtiyaç olduğu belirtilmiştir. Lazer yardımlı LRP'nin ise uygulanabilir olmasına rağmen hala deneysel olduğu belirtilmektedir. LP için ise herhangi bir öneride bulunulmamaktadır.

Literatür verileri incelendiğinde olumlu geri bildirimler alınmış olsa da; ürolojik laparoskopik cerrahide lazer kullanımı rutin klinik kullanımda halen kabul görmemiştir ve rutin alternatif bir yöntem olması için randomize prospektif çalışmalara ihtiyaç duyulmaktadır.

\section{Kaynaklar}

1. Yıldırım B, Ateş M. Laparoskopik uygulamalarda lazer. Turk Urol Seminerleri 2:146-148, 2011.

2. Gianduzzo T. Lasers in laparoscopic surgery. New Technologies in Urology, 1st Edition, Editor: Dasgupta P, Fitzpatrick JM, Kirby R, Gill IS. London, Springer-Verlag London, 2010; 79-89.

3. Malloy TR, Schultz RE, Wein AJ, et al. Renal preservation utilizing neodymium:YAG laser. Urology 27:99-103,1986.

4. Korhonen AK, Talja M, Karlsson H, et al. Contact Nd: YAG laser and regional renal hypothermia in partial nephrectomy. Ann Chir Gynaecol Suppl 206: 59-62, 1993.

5. Merguerian PA, Seremetis G. Laser assisted partial nephrectomy in children. J Pediatr Surg 29:934-936, 1994.

6. Gruschwitz T, Stein R, Schubert J, et al. Laser supported partial nephrectomy for renal cell carcinoma. Urology 71:334-336, 2008.

7. Lotan Y, Gettman MT, Ogan K, et al. Clinical use of the holmium: YAG laser in laparoscopic partial nephrectomy. J Endourol 16:289-292, 2002.

8. Ogan K, Wilhelm D, Lindberg G, et al. Laparoscopic partial nephrectomy with a diode laser: porcine results. J Endourol 16:749-753, 2002.

9. Knezevic N, Kulis T, Maric M, et al. Laparoscopic partial nephrectomy with diode laser: a promising technique. Photomed Lazer Surg 32:101-105, 2014.
10. Zhou XF, Ding ZS, Wang JF, et al. Laparoscopic partial nephrectomy by diode lazer with highly selective clamping of segmental renal arterial. CMJ 128:2262-2264, 2015.

11. Moinzadeh A, Gill IS, Rubenstein M, et al. Potassiumtitanyl-phosphate laser laparoscopic partial nephrectomy without hilar clamping in the survival calf model. J Urol 174:1110-1114, 2005.

12. Hindley RG, Barber NJ, Walsh $\mathrm{K}$, et al. Laparoscopic partial nephrectomy using the potassium titanyl phosphate laser in a porcine model. Urology 67:10791083, 2006.

13. Liu M, Rajbabu K, Zhu G, et al. Laparoscopic partial nephrectomy with saline-irrigated KTP laser in a porcine model. J Endourol 20:1096-1100, 2006.

14. Rioja J, Morcillo E, Novalbos JP, et al. Laparoscopic Partial Nephrectomy With Potassium-titanyl-phosphate Laser Versus Conventional Laparoscopic Partial Nephrectomy: An Animal Randomized Controlled Trial. Urology 99:123-130, 2016.

15. Thomas AZ, Smyth L, Hennessey D, et al. Zero ischemia laparoscopic partial thulium laser nephrectomy. J Endourol 27: 1366-1370, 2013.

16. Sciarra A, Heland MG, Minisola F, et al. Thulium laser supported nephron sparing surgery for renal cell carcinoma. J Urol 190:698-701, 2013.

17. Chauhan S, Coelho RF, Rocco B, et al. Techniques of Nerve-sparing and potency outcomes following robotassisted laparoscopic prostatectomy. Int Braz J Urol 36: 259-272, 2010.

18. Ong AM, Su L, Varkarakis I, et al. Nerve sparing radical prostatectomy: effects of hemostatic energy sources on the recovery of cavernous nerve function in a canine model. J Urol 172(4 Pt 1):1318-1322, 2004.

19. Gianduzzo TR, Chang CM, El-Shazly, et al. Lazer nervesparing laparoscopic radical prostatectomy: a feasibility study. BJU Int 99: 875-879, 2007.

20. Gianduzzo TR, Colombo JR, Haber GP, et al. KTP lazer nerve sparing radical prostatectomy: comparison of ultrasonic and cold scissor dissection on cavernous nerve function. J Urol 181: 2760-2766, 2009.

21. Wolf JS Jr, Soble JJ, Nakada SY, et al. Comparison of fibrin glue, laser weld, and mechanical suturing device for the laparoscopic closure of ureterotomy in a porcine model. J Urol 157:1487-1492, 1997.

22. Barrieras D, Reddy PP, McLorie GA, et al. Lessons learned from laser tissue soldering and fibrin glue pyeloplasty in an in vivo porcine model. J Urol 164(3 Pt 2):1106-1110, 2000.

23. Shumalinsky D, Lobik L, Cytron S, et al. Laparoscopic laser soldering for repair of ureteropelvic junction obstruction in the porcine model. J Endourol 18:177-181, 2004.

24. Herrmann TR, Liatsikos EN, Nagele U, et al. EAU Guidelines on Laser Technologies. Eur Urol 61:783-795, 2012.

Yazışma Adresi:

Altuğ Tuncel,

Sağlık Bilimleri Üniversitesi, Ankara Numune Ĕ̆itim ve Araştırma Hastanesi, Üroloji Kliniğ̈i, 06120, Sihhiye, Ankara

Tel: +903125085055

e-mail: tuncelaltug@yahoo.com 